\title{
Genetic Polymorphism of Long Noncoding RNA H19 in Breast Cancer in Egyptian Females
}

\author{
N.I.Azab ${ }^{1}$, G.E.Saleh ${ }^{2}$, S.A.Mohammed ${ }^{1}$, S.M.Abd El Rahman ${ }^{1}$ and N.M Mohamed ${ }^{1}$ \\ ${ }^{1}$ Biochemistry, Molecular BiologyDept., Faculty of Medicine, Benha Univ., Benha, Egypt \\ ${ }^{2}$ General Surgery, Dept., Faculty of Medicine, Benha Univ., Benha, Egypt \\ E-Mail:norhan@gmail.com
}

\begin{abstract}
Breast cancer (BC) is the most common type of cancer encountered in women and the second leading cause of death after lung cancer. Thus, BC is a serious health concern for all women. The long noncoding RNA (lncRNA) H19 is a maternally expressed imprinted gene that plays important roles in tumorigenesis, progression, and metastasis. IncRNA H19 has been well studied playing an important role in BC progress and the expression of H19 may service as a diagnostic target for BC. Polymorphisms in lncRNA H19 have been shown to be associated with the risk of cancer, but the findings are inconsistent. The present study aimed to investigate the effect of lncRNA H19 single nucleotide polymorphism (SNP) rs217727 in Egyptian breast cancer females. We determined the genotypic frequency of lncRNA H19 rs217727 in 100 breast cancer patients, 50 women with benign lesion and 50 healthy individuals using PCR and gel electrophoresis.We found significant association between lncRNA H19 rs217727 polymorphism and BC as the T allele was significantly higher in BC patients than benign and control groups.It is indicated in this research that rs 217727 is statistically correlated with the Bsusceptibility of BC in Egyptian females.
\end{abstract}

Keywords: Breast cancer, IncRNA H19, Single nucleotide polymorphism.

\section{Introduction}

Breast cancer $(\mathrm{BC})$ is the most frequently diagnosed malignant tumor and the first leading cause of cancer death among women [1]. BC is the most common malignancy in women in the United States and is second only to lung cancer as a cause of cancer death [2]. Among all malignancies, $\mathrm{BC}$ is the most common cancer in Egyptian women. It represents about $38 \%$ of all reported cancer cases in Egyptian females, with an average age of 49.6 per 100,000 populations [3]. The development of $\mathrm{BC}$ is a complex multistep process involving both environmental factors and genetic variations. It is well established that age, obesity, previous benign breast disease, positive family history of BC, and female menstrual and reproductive status are associated with the development of BC [4]. These studies have led to the identification of Long noncoding RNA (IncRNA), which was transcribed from noncoding sites and may be increased the susceptibility of risk cancer [5].

One of the LncRNA found in humans is H19. Being adjacent to the insulin-like growth factor 2 (IGF2) gene, and is expressed only from the maternally inherited chromosome, while IGF2 is expressed only from the paternally inherited chromosome. H19, a lncRNA, is the transcription product of the $\mathrm{H} 19$ gene, and diversified transcript variants exist due to alternative splicing. Although H19 RNA molecules can be detected in both the cytoplasm and nucleus, H19 RNA primarily exists in cytoplasm [6]. Gene Ontology (GO) analyses predicted that $\mathrm{H} 19$ is connected with neurogenesis, angiogenesis and inflammation through DNA transcription, RNA folding, methylation and gene imprinting. The aberrant expression of H19 is associated with multiple diseases, including carcinoma, sarcoma, type 2 diabetes and hypertrophic cardiomyopathy [7].

Accumulating evidence has demonstrated that H19 IncRNA is abnormally expressed and promotes cancer- cell proliferation in many tumors, such as BC and hepatocellular, esophageal, and bladder cancers suggesting an oncogenic function [8]

Recently, studies on the effects of SNPs (single nucleotide polymorphisms) have extended to functional lncRNAs. Some original studies and previous metaanalyses reported the relationship between $\mathrm{H} 19$ rs217727 and cancer risk, but the results were inconsistent. In addition, several recently published studies provide the basis for updating data sets and more accurately evaluating the relationship between $\mathrm{H} 19$ rs217727 and cancer risk. Thus, we performed meta-analysis to explore the association between $\mathrm{H} 19$ polymorphisms and the risk of cancer $[9,10]$.

\section{Material and methods \\ 2.1 Study subjects}

Fifty apparently healthy volunteer women, 50 women who were histopathologically diagnosed as benign breast lesion and 100 women diagnosed clinically and histopathologically as breast carcinoma with different stages were included in the study. The study was carried out after being approved from the Ethical Committee, Benha Faculty of Medicine. Informed consents were obtained from the included subjects. The subjects were recruited from General Surgery Department, Faculty of Medicine, Benha University Hospital.

\subsection{Sample collection and DNA isolation}

Peripheral blood samples $(2 \mathrm{ml})$ were collected on ethylene diamine tetra-acetic acid (EDTA) in 2 Eppendorf tubes. Genomic DNA was extracted from 100 $\mu 1$ EDTA blood via Quick-gDNA Miniprep kit, Catalog No. D3024 (Zymo research, USA) according to manufacturer's instructions. 


\subsection{PCR amplification}

The extracted DNA concentration was measured by Nanodrop Spectrophotometer 2000 (Thermo-Fisher Scientific, Wilmington, USA). Readings were taken at wave lengths 260 and $280 \mathrm{~nm}$. according to that reported by Wilfinger et al. [11]. The optical density (OD) ratio at $260 \mathrm{~nm}$ and $280 \mathrm{~nm}$ estimates the DNA purity. Pure preparations of DNA have OD260/OD280 of 1.7 - 2.0. The extracted DNA concentration ranged from 20-30 ng DNA/ $\mu$ l.

Polymerase chain reaction-restriction was performed with appropriate primers [12] that flank the 32bpdeletion. The primer set: 5'ACTCACGAATCGGTCTGGAAGGTG3'and 5'ATGTGGTGGCTGGTGGTCAACGGT-3’ were used. PCR was performed usingVeriti ${ }^{\mathrm{TM}}$ thermocycler (Applied Bio system). 12.5 $\mu$ l Easy taq PCR Super Mix (Transgen biotech, China) $(25 \mu \mathrm{l}), 2.5 \mu \mathrm{l} \mathrm{FP}, 2.5 \mu \mathrm{l} \mathrm{RP}, 5 \mu \mathrm{l}$ DNA template and $15 \mu \mathrm{l}$ nuclease-free $\mathrm{H} 2 \mathrm{O}$ were added for each reaction. PCR was done for 35 cycles, consisting of a $95^{\circ} \mathrm{C}$ for $5 \mathrm{~min}$ as initial denaturation, denaturation at $95^{\circ} \mathrm{C}$ for $30 \mathrm{~s}$, annealing at $60^{\circ} \mathrm{C}$ for $30 \mathrm{~s}$, and further extension at $72^{\circ} \mathrm{C}$ for $5 \mathrm{~min}$. Gel electrophoresis was performed for PCR products on 3\% agarose gel stained with ethidium bromide $(0.3 \mathrm{ug} / \mathrm{ml})$ to check the PCR products at $247 \mathrm{bp}$ fragment. Digestion was done for lncRNA H19 rs217727 by Fast-digest RsrII restriction enzyme (New England Biolabs, England) in $50 \mu$ total volume. Bands were visualized by Alpha InfoTech Gel Documentation System.

\subsection{Statistical analysis}

The analysis of data was determined by $\chi 2$-test and Student's t-test was used to compare means for continuous variables. Microsoft excel 2016 was used. Results were considered significant at $\mathrm{p}<0.05$.

\section{Results}

In this case control study, 100 clinically confirmed breast cancer women, 50 women diagnosed as benign breast lesion and 50 unrelated healthy control women were analysed. The mean ages of patients, benign and controls were $4.43 \pm 10.71,43.5 \pm 12.28$ and $45.32 \pm 12.02$ years respectively. The selected characteristics of the BC cases, benign and controls are presented in Table 1 .

The clinical-pathological features of the BC group are summarized in Table 2. It observed that more than $70 \%$ of patients had positive hormonal receptors (ER, PR and HER2-neu receptors). The majority of patients had node-positive and TNM stage II disease.

Genotype distribution rs217727 lncRNA-H19 polymorphisms are shown in Table 3. It was observed that the $\mathrm{T}$ allele was significantly higher in $\mathrm{BC}$ patients.

The baseline Characteristics of the BC group among different IncRNA-H19 rs217727 genotypes are summarized in Table 4. It was observed that there were no significant differences $(\mathrm{p}>.05)$.

Table (1) Baseline Characteristics of BC women, benign group and Controls.

\begin{tabular}{|c|c|c|c|c|c|c|}
\hline Variables & & $\begin{array}{c}\text { BCpatients } \\
(\text { n.= 100) }\end{array}$ & $\begin{array}{c}\text { Benign } \\
\text { group } \\
(\mathbf{n} .=50)\end{array}$ & $\begin{array}{l}\text { Controls } \\
(n .=20)\end{array}$ & Test & $\mathbf{P}$ \\
\hline & & \multicolumn{5}{|c|}{$($ Mean \pm SD) or $n .(\%)$} \\
\hline Age (years) & & $4.43 \pm 10.71$ & $43.5 \pm 12.28$ & $45.32 \pm 12.02$ & $1.99 \%$ & 0.14 \\
\hline \multirow[t]{2}{*}{ Marital status } & Single & $15(15 \%)$ & $10(20 \%)$ & $10(20 \%)$ & \multirow[t]{2}{*}{0.87} & \multirow[t]{2}{*}{0.65} \\
\hline & Married & $85(85 \%)$ & $40(80 \%)$ & $40(80 \%)$ & & \\
\hline \multicolumn{7}{|l|}{ history } \\
\hline Systemic & No systemic & $21(21 \%)$ & $19(38 \%)$ & $18(36 \%)$ & & \\
\hline \multirow[t]{3}{*}{ seases } & disease HTN & $27(27 \%)$ & $13(26 \%)$ & $10(20 \%)$ & \multirow{3}{*}{7.5} & \multirow{3}{*}{0.28} \\
\hline & DM HTN+DM & $36(36 \%)$ & $11(22 \%)$ & $14(28 \%)$ & & \\
\hline & & $1616 \%)$ & $7(14 \%)$ & $8(16 \%)$ & & \\
\hline Smoking & Yes & $7(7 \%)$ & $3(6 \%)$ & $3(6 \%)$ & 0.12 & 1.0 \\
\hline \multirow{3}{*}{$\begin{array}{l}\text { Contraception } \\
\text { methods }\end{array}$} & No contraception & $23(23 \%)$ & $17(34 \%)$ & $16(32 \%)$ & \multirow[t]{3}{*}{3.28} & \multirow[t]{3}{*}{0.51} \\
\hline & IUCD Pills & $23(23 \%)$ & $11(22 \%)$ & $13(26 \%)$ & & \\
\hline & & $54(54 \%)$ & $22(44 \%)$ & $21(42 \%)$ & & \\
\hline
\end{tabular}

BC: breast cancer, HTN: hypertension, DM: diabetes mellitus, IUCD: intrauterine contraceptive device Student's T test, ${ }^{\text {b. }}$ Chi-square test.

Table (2) Clinical-pathological features of BC females.

\begin{tabular}{lcc}
\hline & $\begin{array}{c}\text { No. of Patients } \\
\text { n.= 100 }\end{array}$ & $\%$ \\
\hline Estrogen receptor status & 75 & $75 \%$ \\
ER +ve & 25 & $25 \%$ \\
ER-ve & & \\
\hline
\end{tabular}


Table (2) Continue

\begin{tabular}{lcc}
\hline Progesterone receptor status & & $71 \%$ \\
PR +ve & 71 & $29 \%$ \\
PR -ve & 29 & $74 \%$ \\
Her 2 neu status & & $26 \%$ \\
Her 2 neu +ve & 74 & \\
Her 2 neu -ve & 26 & $15 \%$ \\
TNM stage at diagnosis & & $40 \%$ \\
I & 15 & $26 \%$ \\
II & 40 & $19 \%$ \\
III & 26 & \\
IV & 19 & $13 \%$ \\
Lymph node status & & $21 \%$ \\
No & 13 & $35 \%$ \\
N1 & 21 & $31 \%$ \\
N2 & 35 & \\
N3 & 31 & $21 \%$ \\
Tumor grade & & $53 \%$ \\
I & 21 & $26 \%$ \\
II & 53 & \\
III & 26 & \\
\hline
\end{tabular}

Table (3) Genotypes \& allele types of rs217727 lncRNA-H19 polymorphism in Egyptian breast cancer females compared to benign and control groups.

\begin{tabular}{lllll}
\hline Variable & $\begin{array}{l}\text { Controls } \\
(\mathbf{n . = 5 0})\end{array}$ & $\begin{array}{l}\text { Benign group } \\
(\mathbf{n = 5 0})\end{array}$ & $\begin{array}{l}\text { BC Patients } \\
(\mathbf{n . = 1 0 0})\end{array}$ & Pvalue \\
\hline rs217727 lncRNA-H19 genotypes & & $4(8 \%)$ & $17(17 \%)$ & \\
TT & $3(6 \%)$ & $20(40 \%)$ & $46(46 \%)$ & 0.087 \\
CT & $19(38 \%)$ & $26(52 \%)$ & $37(37 \%)$ & \\
CC & $28(56 \%)$ & & & \\
rs217727 lncRNA-H19 allele & & $28(28 \%)$ & $80(40 \%)$ & \\
T & $25(25 \%)$ & $72(72 \%)$ & $120(60 \%)$ & 0.014 \\
C & $75(75 \%)$ & & \\
\hline
\end{tabular}

Table (4) Baseline data among different lncRNA-H19 rs217727 genotypes of BC group.

\begin{tabular}{|c|c|c|c|c|c|}
\hline $\begin{array}{l}\text { BC group } \\
(\mathbf{n} .=100)\end{array}$ & & TT (17) & CT(46) & CC (37) & $\mathbf{p}$ \\
\hline & & & (Mean & rn. $(\%)$ & \\
\hline Age (years) & & $47.94 \pm 7.9$ & $49.3 \pm 11.15$ & $50.32 \pm 11.42$ & 0.75 \\
\hline \multirow[t]{2}{*}{ Marital status } & Single & $1(5.9 \%)$ & $8(17.4 \%)$ & $6(16.2 \%)$ & \multirow{2}{*}{0.51} \\
\hline & Married & $16(94.1 \%)$ & $38(82.6 \%)$ & $31(83.8 \%)$ & \\
\hline \multirow[t]{2}{*}{ Family history } & Yes & $4(23.5 \%)$ & $12(26.1 \%)$ & $10(27 \%)$ & \multirow[t]{3}{*}{0.96} \\
\hline & & $2(11.8 \%)$ & $13(28.3$ & $6(16.2 \%)$ & \\
\hline \multirow[t]{3}{*}{ Systemic diseases } & No systemic & $8(47.1 \%)$ & $8(17.4 \%)$ & $11(29.7 \%)$ & \\
\hline & disease HIN & $4(23.5 \%)$ & $17(37 \%)$ & $15(40.5 \%)$ & \multirow{2}{*}{0.29} \\
\hline & DM HTN+DM & $3(17.6 \%$ & $8(17.4 \%)$ & $5(13.5 \%)$ & \\
\hline Smoking & Yes & $2(11.8 \%)$ & $2(4.3 \%)$ & $3(8.1 \%)$ & 0.52 \\
\hline \multirow{3}{*}{$\begin{array}{l}\text { Contraception } \\
\text { methods }\end{array}$} & No contraception & $2(11.8 \%)$ & $12(26.1 \%)$ & $9(24.3 \%)$ & \multirow{3}{*}{0.69} \\
\hline & IUCD & $4(23.5 \%)$ & $12(26.1 \%)$ & $7(18.9 \%)$ & \\
\hline & Pills & $11(64.7 \%)$ & $22(47.8 \%)$ & $21(56.8 \%)$ & \\
\hline
\end{tabular}

\section{Discussion}

H19 might promote carcinogenesis by acting in competitive endogenous RNA or precursors of microRNAs, and was confirmed to be highly upregulated in a variety of cancers, such as BC and hepatocellular, esophageal, and bladder cancers $[8,13]$.

Numerous SNPs have been identified to be associated with an elevated risk of $\mathrm{BC}$, suggesting a significant contribution of inherited factors in $\mathrm{BC}$ 
susceptibility, so identification of additional potential SNPs could have a great impact on risk estimation for $\mathrm{BC}$ and provide earlier application of proper therapeutic strategies to decrease its mortality rate (14). LncRNA H19 has been widely recognized for its aberrant expression profile and role in carcinogenesis, and it is suggested to be a novel biomarker for the diagnosis of cancer [15].

Larger and well-designed studies are required to further confirm the exact role of these specific H19 polymorphisms in cancer development, progression, and severity. H19 rs217727 polymorphism could serve as a marker for and potentially therapeutic target in a variety of cancer subtypes [16]

Our data found that there were association between H19 rs217727 polymorphism and BC and the T allele of rs217727 was significantly higher in BC than benign and control groups.

These results were in agreement with [17], [18] [19] who reported that $\mathrm{T}$ allele carriers have a significantly higher risk for the development of breast cancer and functional SNP rs217727 in H19 is highly likely to be involved in $\mathrm{BC}$ development.

Wang et al. [20] showed that LncRNA H19 rs217727 could increase cancer risk in overall population, as well as in Asians, due to differences in genetic background, and the complex process of cancer formation.

Our data were similar to what conducted by [19]. They found that the frequency of $\mathrm{T}$ allele was significantly higher in breast cancer patients compared to the controls $(\mathrm{P}<0.05)$.

Hassanzarei et al. [18] revealed an association between lncRNA-H19 gene polymorphism and BC risk. In addition, it suggested that the nucleotide changes in lncRNA-H19 may be considered as a potential biomarker for predisposition to $\mathrm{BC}$.

Our data were similar to what conducted by [19] who found that the frequency of $\mathrm{T}$ allele was significantly higher in breast cancer patients compared to the controls $(\mathrm{P}<0.05)$.

In accordance with our data, [16] observed an association between H19 rs217727 polymorphism and cancer susceptibility.

On the other hand, [21], [22], [23] found that the H19 rs217727 polymorphism was not associated with the susceptibility to breast cancer in the studied population. They observed no significant difference in the rs 217727 polymorphism frequency between breast cancer cases and control groups.

As regarding the demographic data between different lncRNA-H19 rs217727 genotypes of BC, our findings closely similar to those reported by [18] who reported that the CT and TT genotypes higher in age $>50$ with non-significant statistical differences $(\mathrm{P}=0.884)$.

Verhaegh et al. [24] found that $\mathrm{rs} 217727$ decreased the susceptibility of breast cancer. This difference may due to the various pathogenesis of different cancers.

Our results may be explained as the polymorphism can generate repercussions at several levels of lncRNA regulation. Some of these repercussions include alterations in transcription regulation expression, change of miRNA target sites and modification of the RNA secondary structure. For example, it is well known that lncRNA H19 interacts with several miRNAs, such as miR-152, miR-675-5p and let-7 in several tumorigenesis processes [25].

\section{Conclusion}

Our findings support an association between H19 rs217727 polymorphisms and BC risk in Egyptian females. The variants of $\mathrm{H} 19$ may be a potential biomarker for predisposition to BC. However, it needs a larger sample size to verify the results.

\section{References}

[1] L.Fan, K.Strasser-Weippl, , J. J. Li, J. St Louis, D. M. Finkelstein, , K. D. Yu Breast cancer in China. The lancet oncology, Vol.15(7),PP.e279e289, 2014.

[2] W. J. Gradishar, B. O. Anderson, R. Balassanian, S. L. Blair, H. J. Burstein, A.CyrInvasive breast cancer version 1.2016, NCCN clinical practice guidelines in oncology. Journal of the National Comprehensive Cancer Network, Vol.14(3),PP.324-354, 2016.

[3] S.Dey, A. S. Soliman, A.Hablas, I. A. Seifeldein, K. Ismail, M. Ramadan. Urbanrural differences in breast cancer incidence in Egypt (1999-2006). The Breast, 19(5), 417423.Lee S, Margolin K. Cytokines in cancer immunotherapy. Cancers (Basel), Vol.3(4), PP.3856-3893, 2010.

[4] F. Balkwill. Cancer and the chemokine network. Nature Reviews Cancer, Vol.4(7),PP.540-550, 2004.

[5] L.Rahib, B. D. Smith, R.Aizenberg, A. B. Rosenzweig, J. M. Fleshman, L. M. Matrisian. Projecting cancer incidence and deaths to 2030: the unexpected burden of thyroid, liver, and pancreas cancers in the United States. Cancer research, Vol.74(11),PP.2913-2921, 2014.

[6] E.Raveh, I. J. Matouk, M.Gilon, A.Hochberg. The H19 Long non-coding RNA in cancer initiation, progression and metastasis-a proposed unifying theory. Molecular cancer, Vol.14(1),PP.184, 2015.

[7] K. V. Prasanth, D. L. Spector. Eukaryotic regulatory RNAs: an answer to the 'genome complexity'conundrum. Genes \& development, Vol.21(1),PP.11-42, 2007.

[8] T.Gao, B. He, Y.Pan H19 DMR methylation correlates to the progression of esophageal squamous cell carcinoma through IGF2 imprinting pathway. Clin Transl Oncol, Vol.16(4),PP.410-417, 2014.

[9] H.Sun, G. U. O. Wang , Y. A. N. Peng, Y. Zeng, Q. N. Zhu, T. L. Li, Y. S. Zhu. H19 lncRNA mediates 17 $\beta$-estradiol-induced cell proliferation in MCF-7 breast cancer cells. 
Oncology reports, Vol.33(6),PP.3045-3052, 2015.

[10]Z. Yuan, Y. Yu, B. Zhang, L. Miao, L. Wang, H. Zhao, Yuan Genetic variants in lncRNA H19 are associated with the risk of oral squamous cell carcinoma in a Chinese population. Oncotarget, Vol.9(35),PP.23915, 2018.

[11] W. W. Wilfinger, K. Mackey, P. Chomczynski. Effect of $\mathrm{pH}$ and ionic strength on the spectrophotometric assessment of nucleic acid purity. Biotechniques, Vol.22(3),PP.474-481, 1997.

[12] S. Abdollahzadeh, S. Ghorbian. Association of the study between LncRNA-H19 gene polymorphisms with the risk of breast cancer. Journal of clinical laboratory analysis, Vol.33(3),PP.22826, 2019.

[13]M.Luo, Z.Li, W.Wang, Y.Zeng, Z.Liu, J. Qiu. Upregulated H19 contributes to bladder cancer cell proliferation by regulating ID2 expression. The FEBS journal, Vol.280(7),PP.1709-1716, 2013.

[14]L. Fejerman, N.Ahmadiyeh, D.Hu, S.Huntsman, K. B. Beckman, J. L. Caswell, E. Ziv. Genome-wide association study of breast cancer in Latinas identifies novel protective variants on $6 \mathrm{q} 25$. Nature communications, Vol.5(1),PP.1-8, 2014.

[15] S.Chen, D.Bu, Y.Ma, J. Zhu, G.Chen, L.Sun, P. Wang. H19 overexpression induces resistance to $1,25(\mathrm{OH}) 2 \mathrm{D} 3$ by targeting VDR through miR-675-5p in colon cancer cells. Neoplasia, Vol.19(3), PP.226-236, 2017.

[16]M. Hashemi, S.Karami, S. Sarabandi, A.Moazeni-Roodi, A.Małecki, S. Ghavami, E. Wiechec. Association between PD-1 and PD-L1 polymorphisms and the risk of cancer: a metaanalysis of case-control studies. Cancers, Vol.11(8),PP.1150, 2019.

[17] Y. Lin, F. Fu, Y. Chen, , W. Qiu, S. Lin, P. Yang, C. Wang. Genetic variants in long noncoding RNA H19 contribute to the risk of breast cancer in a southeast China Han population. OncoTargets and therapy, Vol.10,PP.4369-4378, 2017.

[18] S. Hassanzarei, M. Hashemi, H. Sattarifard, S. M. Hashemi, G.Bahari. Genetic polymorphisms in long noncoding RNA H19 are associated with breast cancer susceptibility in Iranian population. Meta Gene, Vol.14,PP.1-5, 2017.

[19] C.Mathias, L. E. Garcia, M. D.Teixeira, A. F. Kohler, R. D. Marchi, J. F. Barazetti, J. C. de Oliveira. Polymorphism of lncRNAs in breast cancer: Meta-analysis shows no association with susceptibility. The Journal of Gene Medicine, Vol.22(12),PP.3271, 2020.

[20]X.Wang, J.Zhong, F.Chen, , K.Hu, , S.Sun, , Y.Leng, Q. Luo. Association between lncRNA H19 rs217727 polymorphism and the risk of cancer: an updated meta-analysis. BMC medical genetics, Vol.20(1),PP.1-12, 2019.

[21]Z.Xia, R.Yan, F. Duan, C.Song, P.Wang, K. Wang. Genetic polymorphisms in long noncoding RNA H19 are associated with susceptibility to breast cancer in Chinese population. Medicine, Vol.95(7),PP.2771, 2016.

[22] Y.Lu, L.Tan, N.Shen, J.Peng, C. Wang, Y.Zhu, X.Wang. Association of lncRNA H19 rs217727 polymorphism and cancer risk in the Chinese population: a meta-analysis. Oncotarget, 7(37), 59580, 2016.

[23]Z. Lv, Q.Xu, Y.Yuan. A systematic review and meta-analysis of the association between long non-coding RNA polymorphisms and cancer risk. Mutation Research/Reviews in Mutation Research.VOL. 771,PP.1-14, 2017.

[24] G. W. Verhaegh, L.Verkleij, S. H. Vermeulen, M.den Heijer, J. A.Witjes, L. A. Kiemeney. Polymorphisms in the $\mathrm{H} 19$ gene and the risk of bladder cancer. European urology, Vol. 54(5),PP.1118-1126, 2008.

[25]Z. X.Zhang, X. Tong, W. N. Zhang, W. N. Fu. Association between the HOTAIR polymorphisms and cancer risk: an updated meta-analysis. Oncotarget, Vol.8(3),PP.4460, 2017. 